\title{
SUPEROVULAÇÃO E VIABILIDADE DE EMBRIÕES DE OVELHAS SANTA INÊS ALIMENTADAS COM ÁCIDOS GRAXOS ESSENCIAIS ${ }^{1}$
}

\author{
Superovulation and Embryos Viability of Santa Ines Ewes Fed \\ With Essential Fatty Acids
}

\author{
Luiz Carlos Tadeu Capovilla ${ }^{2}$ \\ Luiz Paulo Rigolon ${ }^{2}$ \\ Fábio Luiz Bim Cavalieri ${ }^{2}$ \\ Francisco de Assis Fonseca de Macedo 3 \\ Karina Perehouskei Albuquerque \\ Fábio José Lourenço ${ }^{4}$ \\ Graziela Santello ${ }^{4}$
}

\section{Resumo}

Verificou-se o número de corpos lúteos (CL), número de estruturas embrionárias e viabilidade dos embriões em ovelhas alimentadas com fontes de ácidos graxos ômega 3 ou ômega 6. Utilizou-se 24 ovelhas Santa Inês divididas em três tratamentos: T1-Controle, T2- LAC-100 ${ }^{\circledR}$ (lab.Yakult), T3- Linhaça em grão. As dietas eram isoenergéticas (60\% NDT), variando a fonte de ácidos graxos. Trinta dias após receberem a alimentação controlada, cada doadora recebeu um implante auricular de progestágeno (Crestar ${ }^{\circledR}$-lab.Intervet), marcando o $\mathrm{D}_{0}$ do tratamento hormonal. No $\mathrm{D}_{12}$ iniciou-se a superovulação com 250 U.I. de hormônio folículo estimulante (FSH-Pluset ${ }^{\circledR}$-lab.Serono) em doses decrescentes. No $\mathrm{D}_{14}$ retirou-se o progestágeno e aplicou-se $150 \mu \mathrm{g}$ de D-Cloprostenol, análogo sintético da Prostaglandina $\mathrm{F}_{2} \alpha$ (Croniben ${ }^{\circledR}$-lab.Biogenesis). As doadoras manifestaram estro no $\mathrm{D}_{16}$ pela manhã e foram cobertas 12 e 24 horas após, com três reprodutores da mesma raça. No $\mathrm{D}_{23}$ realizaram-se as colheitas cirúrgicas dos embriões. O número de corpos lúteos em cada ovário foi anotado. Os cornos uterinos foram lavados com $50 \mathrm{ml}$ de solução Dulbecco modificado (DMPBS) e o efluente depositado em placas de Petry. As estruturas encontradas foram classificadas quanto ao estágio de desenvolvimento e qualidade. Não houve efeito $(\mathrm{P}>0,05)$ de tratamento no número de corpos lúteos ou produção de estruturas totais; mas houve efeito $(\mathrm{P}<0,05)$ quanto à viabilidade dos embriões em favor do grupo Lac-100, fonte de ômega 6. As fontes de ômega 3 ou ômega 6 não melhoraram a resposta superovulatória, mas a fonte de ômega 6 melhorou a viabilidade dos embriões.

Palavras-chave: Embriões; Lipídeo; Reprodução; Ômega-3; Ômega-6.

1 Parte da tese de Doutorado do primeiro autor pelo Programa de Pós-Graduação em Zootecnia (PPZ) da Universidade Estadual de Maringá (UEM)

2 Professor Doutor do Curso de Medicina Veterinária do Centro Universitário de Maringá (CESUMAR). E-mail: fbim@bol.com.br

3 Professor Doutor do Departamento de Zootecnia (DZO) e Programa de Pós-Graduação em Zootecnia da Universidade Estadual de Maringá (Orientador). E-mail: fafmacedo@uem.br

4 Aluno de Doutorado do Programa de Pós-Graduação em Zootecnia (PPZ) da Universidade Estadual de Maringá (UEM) 


\section{Abstract}

The number of corpus luteum (CL), embryonary structures, and the viability of embryos were verified in ewes that received sources of fatty acids Omega 3 or Omega 6. Twenty four ewes were divided in three experimental groups: T1-Control; T2-LAC-100 (lab. Yakult); and T3-Linseed grains. The rations were isoenergetic with variable sources of fatty acids. Thirty days after the administration of controlled ration, each donor sheep received an ear prostegerone (Crestar ${ }^{\circledR}$-lab.Intervet) implant, indicating $\mathrm{D}_{0}$ of the hormonal treatment. The superovulatory process started at $\mathrm{D}_{12}$ with the administration of $250 \mathrm{UI}$ of Follicle Stimulating Hormone (FSHPluset ${ }^{\circledR}$-lab.Serono) in decreasing doses. On $\mathrm{D}_{14}$ the prostegerone product was removed and was aplicated $150 \mu \mathrm{g}$ of D-Cloprostenol, analog synthetic of Prostaglandin $\mathrm{F}_{2} \alpha$ (croniben ${ }^{\circledR}$-lab.Biogenesis). The donors showed estrus in the morning of $\mathrm{D}_{16}$ and were placed to ram 12 and 24 hours later, males of the same breed. On $\mathrm{D}_{23}$ surgical collection of embryos was realized, and the number of corpus luteum present in each ovary was recorded. The uterine horns were flushed using $50 \mathrm{ml}$ of modified Dulbecco solution (DMPBS), the effluent placed in Petry Dishes. The structures observed were collected and the quality and development of the embryonary structures were classified. No effect $(\mathrm{P}>0.05)$ of the treatment on the number of corpus luteum or total number of structures was observed, but had effect $(\mathrm{P}<0.05)$ in the embryos viability in the Lac-100 group (omega 6). The Omega 3 or Omega 6 sources did not improve the superovulatory response, but omega 6 source improved the viability of the embryos.

Keywords: Embryo; Lipids; Reproduction; Omega-3; Omega-6.

\section{Introdução}

Avanços significativos foram obtidos nos últimos anos na tecnologia da produção e posterior transferência de embriões em ovinos. Para que ocorra melhoramento genético, torna-se necessária a reposição de animais com baixo mérito genético por aqueles geneticamente superiores (FREITAS, 2003).

O procedimento da superovulação, seguida de colheita e transferência de embriões (TE) para receptoras previamente preparadas, provou ser uma maneira eficiente de aumentar a contribuição de fêmeas geneticamente superiores para o pool de genes da população (FREITAS, 2003).

Alguns fatores interferem na performance reprodutiva dos animais domésticos, dentre eles a nutrição, que vem se destacando como um dos mais importantes. Dentre os fatores nutricionais relacionados com a reprodução de fêmeas de animais de produção, a inclusão de gorduras na dieta tem sido estudada, principalmente em vacas (STAPLES et al., 1996).

Segundo Staples et al. (1996), o aumento da concentração de gordura na dieta (acima de 3\% da matéria seca) tem influência positiva no status reprodutivo das vacas leiteiras. A resposta positiva inclui o aumento da concentração plasmática de progesterona, aumento no número de folículos ovarianos, aumento no tamanho do folículo ovulatório e concomitantemente um aumento na taxa de gestação.
Vários trabalhos com bovinos têm mostrado que a suplementação com gordura regula diferencialmente o crescimento folicular, mediado por mudança nas concentrações sangüíneas de insulina, HDL-colesterol, GH e IGF-I no fluído folicular.

Thomas et al. (1997) e Stanko et al. (1997) observaram um aumento no número de folículos médios nos ovários de vacas que receberam gordura na dieta (óleo de peixe, soja e gordura animal). Esse aumento no número de folículos poderia levar a um aumento no número de embriões produzidos.

Diante deste fato, Ryan et al. (1992) hipotetizaram que ao suplementarem novilhas com ácidos graxos poliinsaturados, poderia haver um aumento no número de folículos potencialmente disponíveis para responder aos tratamentos superovulatórios. Esses autores realizaram um experimento com 55 novilhas, alimentadas com duas dietas: uma normal e outra com alta quantidade de ácidos graxos poliinsaturados $(5,4 \%)$ provenientes do óleo de soja, verificando que houve aumento no número de folículos médios, do colesterol total e de progesterona no fluído folicular, apesar de não ter ocorrido variação na resposta superovulatória e no número e qualidade dos embriões coletados. Todavia, afirmaram que a presença de um folículo dominante no $6^{\circ}$ dia do ciclo estral pode ter suprimido o crescimento dos folículos mediante a superovulação. 
Thomas e Willians (1996) tentaram diminuir o efeito do folículo dominante, puncionandoo quatro dias após o estro. Os autores trabalharam com 21 novilhas mestiças de 18 a 20 meses de idade, alimentadas com três dietas: uma controle e outras duas suplementadas com óleo de soja (insaturado) ou gordura animal (saturado), por um período de 35 a 40 dias. Após 20 dias de tratamentos, os animais foram sincronizados com prostaglandina $\mathrm{F}_{2} \alpha$ e a população folicular foi monitorada com ultra-som via retal por 4 dias, sendo que no quarto dias após o estro, o folículo dominante foi aspirado e as novilhas foram tratadas com FSH para induzir a superovulação. Os autores concluíram que os animais alimentados com gordura animal e óleo de soja aumentaram o número de folículos médios e a concentração sangüínea de GH em relação à dieta controle, mas não houve efeito na produção de embriões.

Coscioni et al. (2002) avaliaram o efeito de três níveis de gordura na dieta $(4,0 \% ; 6,0 \%$ e $8,0 \%$ de extrato etéreo) na produção de embriões em vacas da raça Jersey, produzindo 25 litros de leite/dia. Os autores verificaram que o número de embriões coletado por vaca foi maior para os animais alimentados com dieta contendo 8,0\% de EE (5,3 embriões) quando comparado aos animais alimentados com $6,0 \%$ e $4,0 \%$ de $\operatorname{EE}(3,9$ e 0,3 embriões/vaca). Todavia, o número de embriões de níveis 1 e 2 foi maior nos animais alimentados com a dieta contendo $4,0 \%$ e $8,0 \%$ de EE e menor para o tratamento com $6,0 \%$ de EE. Os autores concluíram que o nível moderado de gordura na dieta foi detrimental para o número e qualidade dos embriões.

Petit et al. (1998) verificaram que a fonte de ácidos graxos na dieta, ômega 6 (ácido linoléico) ou ômega 3 (ácido linolênico), tem uma relação positiva com a taxa de prenhez. Os autores encontraram que vacas leiteiras de alta produção apresentaram $50 \%$ de gestação quando foram alimentados com fontes de ácidos graxos ômega 6 (LAC-100) e 89\% de gestação para as vacas alimentadas com fontes de ácidos graxos ômega 3, (grão de linhaça). Entretanto, não se sabe se o perfil de ácidos graxos da dieta poderia afetar a qualidade dos embriões em um programa de transferência.

Trabalhando com ovinos, Zeron et al. (2002) observaram que, ao fornecer óleo de peixe na dieta de ovelhas, aumentou o número e qualidade de ovócitos, bem como o perfil de ácidos graxos poliinsaturados na sua membrana plasmática.

Especificamente em ovinos, o número de trabalhos sobre a influência da manipulação da dieta por meio de suplementação com ácidos graxos poliinsaturados são escassos. Logo, o objetivo deste trabalho foi verificar o número de corpos lúteos, o número de estruturas embrionárias e a qualidade dessas estruturas em ovelhas da raça Santa Inês alimentadas com sementes de Linhaça, fonte de ômega-3, e LAC-100, fonte de ômega-6.

\section{Material e métodos}

\section{Local, data e dados climatológicos}

O experimento foi realizado no Centro de Pesquisa do Arenito, da Universidade de Maringá, no município de Cidade Gaúcha, Noroeste do Paraná, nos meses de maio e junho de 2004 e repetido nos meses de setembro e outubro de 2005. Os dados climatológicos médios dos períodos foram, do primeiro: a temperatura de $17,2^{\circ} \mathrm{C}$, a radiação de 139,5 w.m. ${ }^{-2}$, a umidade relativa do ar de $89,7 \%$, a precipitação de $8,1 \mathrm{~mm}^{3}$, e a velocidade do vento de $0,33 \mathrm{~m} . \mathrm{s}^{-1}$; e do segundo: a temperatura de $21^{\circ} \mathrm{C}$, a radiação de $161,1 \mathrm{w} \cdot \mathrm{m}^{-2}$, a umidade relativa do ar de $85,2 \%$, a precipitação de 10,3 $\mathrm{mm}^{3}$ e a velocidade do vento de $0,64 \mathrm{~m} \cdot \mathrm{s}^{-1}$.

\section{Animais e tratamentos}

Foram utilizadas 24 ovelhas como doadoras de embriões, todas com característica racial padrão da raça Santa Inês, multíparas e cíclicas, com escore corporal médio 3 (escala 1 a 5) e peso médio de $42 \mathrm{~kg}$. Esses animais foram distribuídos aleatoriamente em três tratamentos, cada um contendo oito animais: T1-Controle (CON); T2-Linhaça em grão (LIN) e T3-Lac-100 (LAC).

\section{Dietas experimentais}

A dieta fornecida para os animais está presente na Tabela 1 e a composição centesimal na Tabela 2. 


\section{TABELA 1 - Dieta experimental.}

Table 1 - Experimental diets.

\begin{tabular}{llll}
\hline Ingrediente & \multicolumn{2}{c}{ Quantidade (em Kg) na composição da dieta } \\
\cline { 2 - 4 } & Controle & Linhaça & LAC-100 \\
\hline Capim Aruana & ad libitum & ad libitum & ad libitum \\
Resíduo de Fecularia & 2,00 & 2,00 & 2,00 \\
Semente de Linhaça & - & 0,03 & - \\
LAC-100 & - & - & 0,02 \\
\hline
\end{tabular}

TABELA 2 - Composição química (\% MS) dos alimentos.

Table 2 - Feed chemical composition (\%DM).

\begin{tabular}{llllll}
\hline Ingredientes & MS & PB & EE & FDN & MM \\
\hline Capim Aruana & 53,32 & 4,97 & - & 75,00 & - \\
Resíduo de fecularia & 12,00 & 3,00 & 0,47 & 9,36 & 1,61 \\
Semente de linhaça & 93,09 & 28,91 & 40,96 & 15,13 & 3,79 \\
LAC-100 & 95,00 & 0,00 & 82,00 & - & 5,00 \\
\hline
\end{tabular}

Os animais receberam os tratamentos especificados na Tabela 1 , no período das 9 h00 às 16 h00 permaneceram em pastagens formadas com capim Aruana (Panicum maximum cv. IZ-5) e duas vezes ao dia, pela manhã e à tarde, receberam ração composta pelo resíduo de fécula de mandioca acrescido da semente de linhaça ou LAC-100, de acordo com o tratamento proposto, durante os 30 dias que antecederam o início da sincronização do estro e superovulação até o dia da colheita de embriões.

\section{Tratamento superovulatório}

Trinta dias após iniciado o tratamento alimentar, tanto as doadoras quanto as receptoras receberam um implante auricular de progestágeno contendo $5 \mathrm{mg}$ de norgestomet, Crestar ${ }^{\circledR}$ do laboratório Intervet, marcando o $\mathrm{D}_{0}$ do tratamento hormonal. No décimo segundo dia após terem recebido esse implante $\left(\mathrm{D}_{12}\right)$, iniciou-se nas ovelhas doadoras o processo de superovulação por meio da aplicação intramuscular do hormônio folículo estimulante (F.S.H.), Pluset巴 do laboratório Serono, na dosagem de 250 U.I. por doadora, diluídos em $20 \mathrm{ml}$ de solução fisiológica $\left(12,5 \mathrm{UI} \cdot \mathrm{ml}^{-1}\right)$. As 250 UI do FSH foram administradas em dosagem decrescente, duas vezes ao dia, às 7h00 e 18h00, durante quatro dias consecutivos, sendo que no primeiro dia de superovulação cada animal recebeu 100 U.I. ( $4 \mathrm{ml}$ pela manhã e $4 \mathrm{ml}$ à tarde), 75 UI no segundo dia ( $3 \mathrm{ml}$ e $3 \mathrm{ml}$ ), 50 UI no terceiro dia ( $2 \mathrm{ml}$ e $2 \mathrm{ml}$ ) e $25 \mathrm{UI}$ no quarto dia ( $1 \mathrm{ml}$ e 1 $\mathrm{ml})$. Durante as aplicações, foram utilizadas seringas descartáveis de cinco centímetros cúbicos (5cc) acopladas às agulhas hipodérmicas descartáveis 25x8. No momento da sexta aplicação do FSH, retirou-se o implante de progestágeno das doadoras. Após a retirada dos implantes progestágenos, todos os animais receberam uma aplicação intramuscular de $150 \mu \mathrm{g}$ de D-Cloprostenol, Croniben ${ }^{\circledR}$ do laboratório Biogenesis, análogo sintético da prostaglandina $\mathrm{F}_{2} \alpha\left(\operatorname{Pgf}_{2} \alpha\right)$. Durante o período da tarde do décimo quinto dia $\left(\mathrm{D}_{15}\right)$ e da manhã do décimo sexto dia $\left(\mathrm{D}_{16}\right)$, as doadoras foram observadas quanto à manifestação estral por meio da utilização de rufiões vasectomizados, sem raça definida. Os rufiões foram cirurgicamente preparados de forma a impedir a exposição peniana por meio do estreitamento de seu conduto. Todas as doadoras manifestaram estro no $\mathrm{D}_{16}$ pela manhã e foram cobertas na tarde do mesmo dia e pela manhã do dia seguinte $\left(D_{17}\right)$ com montas dirigidas. Para a cobertura das doadoras, foram utilizados 
três reprodutores da raça Santa Inês, considerados aptos à reprodução após realização de exames andrológicos, sete dias antes das coberturas. Na segunda cobertura, as ovelhas receberam os mesmos reprodutores utilizados no dia anterior. No $\mathrm{D}_{23}$ (sétimo dia após o inicio do estro e da cobertura), as ovelhas doadoras foram submetidas ao processo cirúrgico de colheita de embriões.

\section{Colbeita dos embriões}

Os animais foram preparados para o procedimento cirúrgico por meio de tricotomia ao redor da linha alba e próximo ao úbere, sedadas com $0,5 \mathrm{ml}$ de cloridrato de xilazina $2 \%$, Roumpum ${ }^{\circledR}$ do laboratório Bayer, realizada anestesia local com aplicação de $25 \mathrm{ml}$ de lidocaína 2\%, Anestésico Bravet ${ }^{\circledR}$, do laboratório Bravet na região da futura incisão e assepsia do local. Depois de devidamente preparadas e contidas, foi realizada uma incisão na linha alba, sendo o aparelho reprodutor composto pelo útero e ovários, expostos manualmente por tração. O número de corpos lúteos presente em cada ovário foi anotado e em seguida foi realizada a colheita dos embriões. Foi utilizada solução Dulbecco modificado (DMPBS) por meio de uma pequena incisão no corpo do útero e com uma sonda de Folley de número 16 direcionada primeiro ao corno direito e em seguida ao corno esquerdo, sem inflar o balão de ar, fazendo pequena pressão com os dedos anteriormente à entrada e à saída de aproximadamente 50 $\mathrm{ml}$ do DMPBS por corno uterino, o qual foi recolhido em placa de Petry 100x20. No término de cada coleta, a solução contendo as estruturas embrionárias foi levada ao microscópio estereoscópio, da marca Nikon, modelo SMZ 2, com aumento de 8 vezes, para a identificação das estruturas. Depois de encontradas, essas foram recolhidas com auxílio de um ton cat catheter e transferidas para uma miniplaca de Petry 35x10 contendo solução de manutenção, DMPBS com $0,4 \%$ de Albumina Bovina Sérica (BSA). Após serem encontradas todas as estruturas, foram analisados de acordo com o manual da IETS - International Embryo Transfer Society (Stringfellow; Seidel, 1998) em infertilizados ou não fecundados (NF), degenerados ou mortos (DEG), mórula de qualidade ou nível 1, 2 ou 3 (Mo n1, Mo n2 ou Mo n3), mórula compacta de qualidade 1, 2 ou 3 (Mc n1, Mc n2 ou Mc n3), blastocisto inicial de qualidade 1, 2 ou 3 (Bi n1, Bi $\mathrm{n} 2$ ou Bi n3), blastocisto de qualidade 1, 2 ou 3 (Bl n1, Bl n2 ou Bl n3), blastocisto expandido de qualidade 1, 2 ou 3 (Be n1, Be n2 ou Be n3) ou blastocisto eclodido ou fora da zona pelúcida de qualidade 1, 2 ou 3 (Bex n1, Bex n2 ou Bex n3). No entanto, neste trabalho foram considerados embriões viáveis todos aqueles que apresentavam nível 1, 2 ou 3, independente do estágio de desenvolvimento.

\section{Análise Estatística}

Para as variáveis número de corpos lúteos no ovário direito, número de corpos lúteos no ovário esquerdo, número de corpos lúteos totais, número de estruturas totais e número de estruturas viáveis, admitiu-se a função de distribuição de probabilidade Poisson e função de ligação logarítmica estimada por meio da metodologia de modelos lineares generalizados, utilizando-se o software GLIM 4.0 (NELDER; WEDDERBURN, 1972). As médias foram comparadas utilizando-se o Teste $t$. Para todas as variáveis, o modelo estatístico foi o mesmo e foram incluídos nestes os fatores tratamento e época.

O modelo estatístico aplicado foi o seguinte:

$$
Y_{i j k}=\mu+T_{i}+A_{j}+T_{i j}+e_{i j k}
$$

Onde:

$\mathrm{Y}_{\mathrm{ij} \mathrm{k}}=$ Observação referente ao animal $\mathrm{k}$, submetido ao tratamento i (i=1,2 e 3), na época j;

$\mathrm{T}_{\mathrm{i}=}$ Efeito do tratamento i (i=1,2 e 3);

$A_{j=}$ Efeito da época $j(j=1,2)$; to e época;

$\mathrm{TA}_{\mathrm{ij}}=$ Efeito da interação entre tratamenservação.

$\mathrm{e}_{\mathrm{ij \textrm {k }}}=$ Erro aleatório associado a cada ob-

\section{Resultados e discussão}

A resposta ao tratamento de superovulação foi determinada por contagem de corpos lúteos presentes nos ovários direito e esquerdo das ovelhas. O número de corpos lúteos nos ovários das ovelhas, conforme tratamentos e épocas, é mostrado na Tabela 3 . 


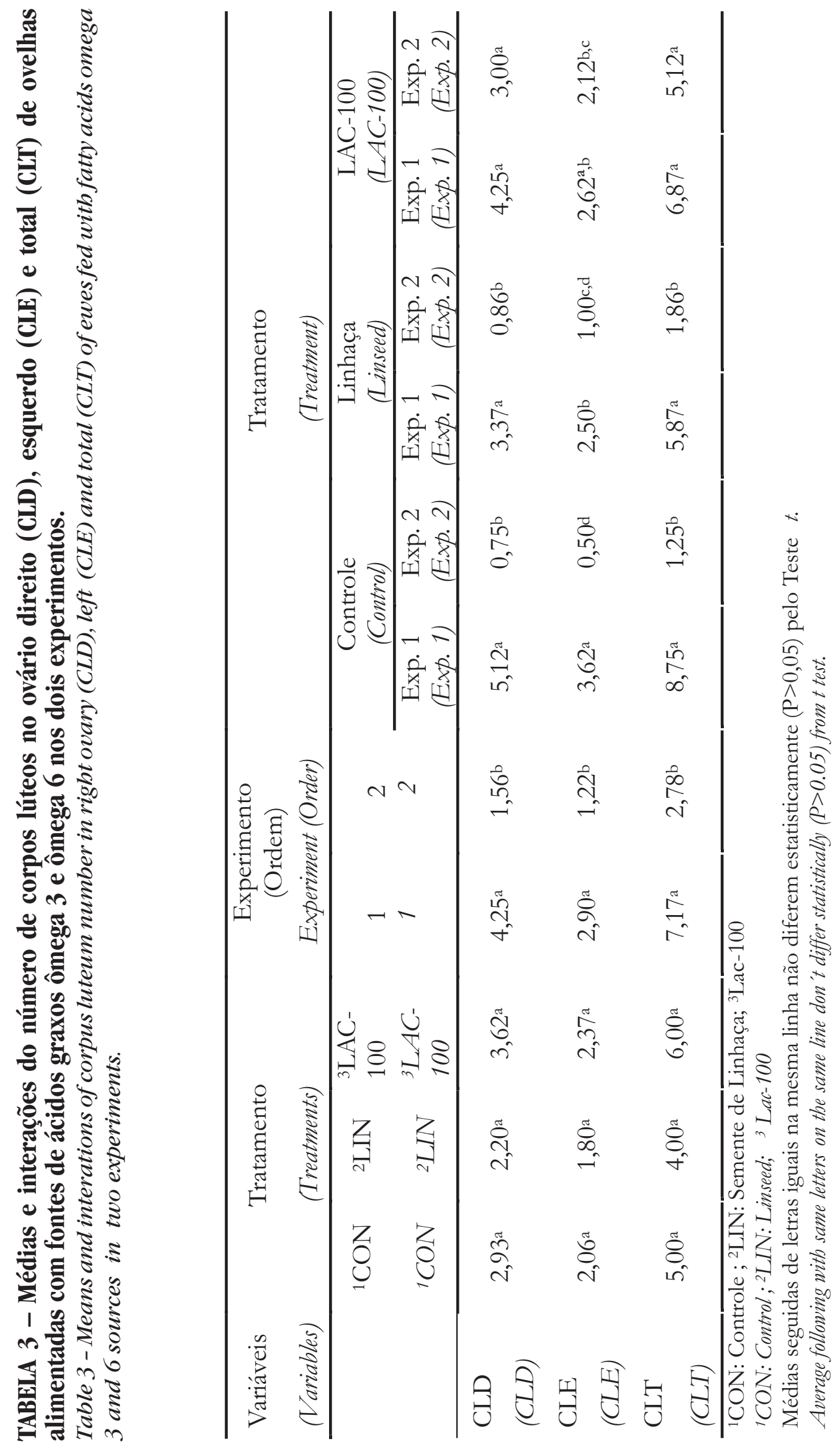


Não houve efeito $(P>0,05)$ de tratamento para número de corpos lúteos no ovário direito, esquerdo e total. Os resultados diferem dos observados por Thomas e Willians (1996), que observaram um aumento no número de folículos trabalhando com novilhas mestiças de 18 a 20 meses de idade, alimentadas com três dietas: um controle e outras duas suplementadas com óleo de soja (insaturado) ou gordura animal (saturado), por um período de 35 a 40 dias. Comportamento idêntico foi observado por Thomas et al. (1997) e Stanko et al. (1997).

Em ovelhas, Zeron et al. (2002) também observaram que ao fornecer óleo de peixe (ômega-3) na dieta dos animais, houve um aumento no número e qualidade de ovócitos. O aumento no número de folículos é interessante em programas de superovulação, pois mais folículos estariam disponíveis para o crescimento e posterior ovulação. Todavia, no presente trabalho, não houve aumento no número de corpos lúteos nas ovelhas alimentadas com gordura na dieta. Assim, também outros tratamentos nutricionais objetivando um aumento no número de embriões, como o nível de energia na dieta, não alteraram a resposta superovulatória em ovinos, de acordo com McEvoy et al. (1995), ou bovinos, segundo Rigolon et al. (2003). Talvez o número de folículos não seja determinante na variação da resposta superovulatória, mas, sim, se estes possuírem receptores para FSH (hormônio folículo estimulante).

Os dados referentes ao número de estruturas totais e número de estruturas viáveis estão ilustrados na Tabela 4.

\section{TABELA 4 - Médias do número de estruturas embrionárias de ovelhas alimentadas com fontes de ácidos graxos ômega 3 e ômega 6 nos dois experimentos.}

Table 4 - Means of the number of embrionary structures of ewes fed with fatty acids omega 3 and 6 sources in two experiments.

\begin{tabular}{|c|c|c|c|c|c|c|c|c|c|c|c|}
\hline \multirow[t]{3}{*}{$\begin{array}{l}\text { Variáveis } \\
\text { (Variables) }\end{array}$} & \multicolumn{3}{|c|}{$\begin{array}{l}\text { Tratamentos } \\
\text { (Treatments) }\end{array}$} & \multicolumn{2}{|c|}{$\begin{array}{c}\text { Experimento } \\
\text { (Ordem) } \\
\text { Experiment (Order) }\end{array}$} & \multicolumn{6}{|c|}{$\begin{array}{l}\text { Tratamento } \\
\text { (Treatment) }\end{array}$} \\
\hline & \multirow{2}{*}{$\begin{array}{c}{ }^{1} \mathrm{CO} \\
\mathrm{N} \\
{ }^{1} \mathrm{CON}\end{array}$} & \multirow{2}{*}{$\begin{array}{l}{ }^{2} \mathrm{LIN} \\
{ }^{2} \mathrm{LIN}\end{array}$} & \multirow{2}{*}{$\begin{array}{l}{ }^{3} \mathrm{LAC}-100 \\
{ }^{3} \mathrm{~L} A C-100\end{array}$} & \multirow{2}{*}{$\begin{array}{l}1 \\
1\end{array}$} & \multirow{2}{*}{$\begin{array}{l}2 \\
2\end{array}$} & \multicolumn{2}{|c|}{$\begin{array}{c}\text { Controle } \\
\text { (Control) }\end{array}$} & \multicolumn{2}{|c|}{$\begin{array}{l}\text { Linhaça } \\
\text { (Linseed) }\end{array}$} & \multicolumn{2}{|c|}{$\begin{array}{l}\text { LAC-100 } \\
(\text { Lac-100) }\end{array}$} \\
\hline & & & & & & $\begin{array}{l}\text { Exp. 1 } \\
\text { (Exp. 1) }\end{array}$ & $\begin{array}{l}\text { Exp. 2 } \\
\text { (Exp. 2) }\end{array}$ & $\begin{array}{l}\text { Exp. 1 } \\
\text { (Exp. 1) }\end{array}$ & $\begin{array}{l}\text { Exp. } 2 \\
\text { (Exp. 2) }\end{array}$ & $\begin{array}{l}\text { Exp. } 1 \\
\text { (Exp. 1) }\end{array}$ & $\begin{array}{l}\text { Exp. } 2 \\
\text { (Exp. 2) }\end{array}$ \\
\hline $\begin{array}{l}\mathrm{N}^{\circ} \text { Estruturas } \\
\text { Totais } \\
\text { (N totals } \\
\text { structures) }\end{array}$ & $2,06^{a}$ & $1,40^{a}$ & $2,56^{a}$ & $3,37^{a}$ & $0,60^{\mathrm{b}}$ & $4,12^{\mathrm{a}}$ & $0,00^{a}$ & $1,75^{a}$ & $1,00^{a}$ & $4,25^{\mathrm{a}}$ & $0,87 \mathrm{a}$ \\
\hline $\begin{array}{l}\mathrm{N}^{o} \text { Estruturas } \\
\text { Viáveis } \\
\text { (N viable } \\
\text { structures) }\end{array}$ & $0,56^{a}$ & $0,93^{a}$ & $2,56^{\mathrm{b}}$ & $2,08^{a}$ & $0,61^{b}$ & $1,12^{\mathrm{a}}$ & $0,00^{\mathrm{a}}$ & $0,87 a$ & $1,00^{a}$ & $4,25^{\mathrm{a}}$ & $0,87 \mathrm{a}$ \\
\hline $\begin{array}{l}{ }^{1} \mathrm{CON} \text { : Contro } \\
{ }^{1} \text { CON: Control, } \\
\text { Médias seguida } \\
\text { Average followin }\end{array}$ & $\begin{array}{l}\text { 2LIN: } \\
\text { IN:Lin } \\
\text { le letras }\end{array}$ & $\begin{array}{l}\text { Sement } \\
\text { seed; }{ }^{3} \text { la } \\
\text { iguais }\end{array}$ & $\begin{array}{l}\text { de Linhaça } \\
100 \\
\text { a mesma lit }\end{array}$ & $\overline{\mathrm{AC}-1}$ & tic & ament & $>0,05)$ & Teste $t$. & & & \\
\hline
\end{tabular}


Na Tabela 4, apesar de não existir diferença significativa $(P>0,05)$ quanto ao número de estruturas totais, observa-se haver efeito de tratamento $(P<0,05)$ na produção de estruturas viáveis. Animais do tratamento LAC 100 produziram maior quantidade de embriões viáveis. Em ovinos não existe relato na literatura avaliando o efeito da gordura, especialmente do LAC 100, fonte de ômega 6 , na dieta na produção de embriões. Os resultados encontrados no presente trabalho contradizem os resultados encontrados em bovinos, nos quais fontes de ômega 3 ou ômega 6 não influenciam a quantidade ou a qualidade dos embriões, mas, sim, os resultados de prenhez.

Cavalieri et al. (2005) não encontraram efeito da utilização de uma dieta rica em ômega 6 (LAC-100) e ou ômega 3 (Linhaça em grão) na produção de embriões em vacas leiteiras de alta produção. Quanto à presença de gordura na dieta, avaliaram o efeito de três níveis de gordura ( $4,0 \%$; 6,0\% e 8,0\% de extrato etéreo) na produção de embriões em vacas da raça Jersey, produzindo 25 litros de leite/dia (COSCIONI et al., 2002). Os autores verificaram que o número de embriões coletados por vaca foi maior para aquelas alimentadas com dieta contendo o maior nível de extrato etéreo, 8,0\%. É importante observar que a inclusão de gordura na dieta pode influenciar variáveis reprodutivas, por estar relacionado também com o aumento das concentrações sangüíneas de proges- terona, hormônio essencial para a manutenção da gestação nos animais domésticos. Aswhort (1995) afirmou que a concentração circulante de progesterona modifica a quantidade e a composição dos polipeptídicos secretados pelo endométrio, muitos dos quais são responsáveis pelo desenvolvimento do embrião e também se relaciona diretamente com a qualidade do ovócito (SAVIO et al., 1993, citados por MCEVOY et al., 1995). Ainda, O'Callaghan et al. (2000) afirmaram que pequenas mudanças na concentração de progesterona no período inicial do desenvolvimento embrionário podem comprometer a sobrevivência do embrião.

A maior concentração de ácido linolênico (ômega 3) na dieta dos animais que receberam Linhaça em grão poderia estar reduzindo à síntese de PGF $_{2 \alpha}$ (PETIT et al., 1998). Isso beneficia somente os embriões do $12^{\circ}$ ao $19^{\circ}$ dia de gestação, quando acontece o reconhecimento materno da gestação. No entanto, no trabalho realizado, os embriões foram coletados sete dias após a monta natural, não existindo qualquer efeito da inclusão de linhaça em grão e, por sua vez, da alteração da síntese de $\mathrm{PGF}_{2 \alpha}$ na qualidade morfológica dos embriões.

Observa-se na Tabela 5 que no experimento 1 a resposta superovulatória e a produção de embriões foram maiores $(\mathrm{P}<0,05)$, quando comparadas ao experimento 2 .

A realização de sucessivas intervenções

\section{TABELA 5 - Quantidade de corpos lúteos totais, estruturas totais e viáveis em ovelhas alimentadas com fontes de ômega 3 e ômega 6 , nos dois experimentos.}

Table 5 - Number of total corpus luteum, total and viable structures in ewes fed with omega 3 and 6 sources, in two experiments.

\begin{tabular}{lcc}
\hline Variáveis & Experimento 1 & Experimento 2 \\
\hline Corpos Lúte os Totais (un.) & $7,16^{\mathrm{a}}$ & $2,78^{\mathrm{b}}$ \\
Estruturas Totais (un.) & $3,37^{\mathrm{a}}$ & $0,60^{\mathrm{b}}$ \\
Estruturas Viáveis (un.) & $2,08^{\mathrm{a}}$ & $0,60^{\mathrm{b}}$ \\
\hline
\end{tabular}

Médias seguidas de letras iguais na mesma coluna não diferem estatisticamente $(\mathrm{P}>0,05)$ pelo Teste $t$.

cirúrgicas nos animais experimentais pode ter levado a um resultado inferior no segundo ano, possivelmente devido à ocorrência de patologias, como aderências e contaminações sépticas, dentre outras. Ressalta-se que patologias como as aderências limitam a movimentação das fímbrias ovarianas e, conseqüentemente, prejudicam a captação dos oócitos. Já as contaminações sépticas alteram as condições do ambiente uterino prejudicando não só a manutenção dos embriões, mas até mesmo a fecundação dos oócitos. 


\section{Conclusões}

Não se recomenda a utilização da linhaça para melhorar a resposta superovulatória e a viabilidade dos embriões em ovelhas da raça Santa Inês, por outro lado, o uso de LAC-100, apesar de não melhorar a resposta superovulatória, melhorou a viabilidade dos embriões.

\section{Referências}

ASWORTH, C. J. Maternal and conceptus factors affecting historophic nutrition and survival of embryos. Livestock Production Science, v. 44, p. 99-105, 1995.

CAVALIERI, F. L. B., et al. Efeitos de duas fontes de gordura (LAC-100 ou linhaça em grão) na dieta na produção de embriões de vacas leiteiras da raça Holoandesa. Acta Scientiae Veterinariae, n. 33, (Supl. 1), p. 217, 2005.

COSCIONE, A. C., et al., Effect of supplemental fat on superovulatory response embryo quality in Jersey cow. Theriogenology, v. 57, n. 1, p. 537, 2002.

FREITAS, V. J. F. Superovulação e transferência de embriões em caprinos e ovinos. Acta Scientiae Veterinariae, v. 31, (Supl.), p. 90-105, 2003.

McEVOY, T. G., et al. Dietary-induced suppression of pre-ovulatory progesterone concentrations in superovulated ewes impairs the subsequent in vivo and in vitro development of their ova. Animal Repoduction Science, v. 39, n. 2, p. 89-107, 1995.

NELDER, J.; WEDDERBURN, R. W. Generalizea linear models. J. R. Statist. Sci. n. 135, p. 370-384, 1972.

O'CALLAGHAN, D.; YAAKUB, H.; HYTTEL, P. Effect of nutrition and superovulation on oocyte morphology, follicular fluid composition hormone concentration in ewes. Journal of Reproduction and Fertility, v. 118, p. 303-313, 2000.

PETIT, H. V., et al. Milk yeld and reproduction of dairy cows fed satured or unsatured fat. Journal of Dairy Science, v. 81, p. 302, 1998.
RIGOLON, L. P., et al. Efeito de diferentes níveis de ingestão de energia sobre a produção e viabilidade de embriões em novilhas e vacas. Revista Brasileira de Zootecnia, v. 6, p. 1304-1310, 2003.

RYAN, D. P.; SPOON, R. A.; WILLIAMS, G. L. Ovarian follicular characteristics, embryo recovery, and embryo viability in heifers fed high-fat diets and treated with follicle-stimulating hormone. Journal of Animal Science, v. 70, p. 3505-3513, 1992.

STANKO, R. L., et al. Follicular growth and metabolic changes in beef heifers fed incremental amounts of polynsaturated fat. Journal of Animal Science, $v$. 75, p. 223, 1997.

STAPLES, C. R.; THETCHER, W. W.; BURKE, J. M. Influence of supplemental fat on reproductive tissues of the dairy cow. Journal of Dairy Science, v. 79, p. 113-123, 1996.

STRINGFELLOW, D. A.; SEIDEL. Manual of the International Embryo Transfer Society (IETS): a procedural guide and general information for the use of embryo transfer technology emphasizing sanitary precautions, 2nd ed. Stringfellow D. A, Seidel SM, USA, p. 67, 1998.

THOMAS, M. G.; BAO, B.; WILLIAMS, G. L. Dietary fats varying in their fatty acid composition differentially influence growth in cows fed isoenergetic diets. Journal of Animal Science, $v$. 75, p. 2512-2519. 1997.

THOMAS, M. G.; WILLIAMS, G. L. Metabolic hormone secretion and FSH-induced superovulatory responses of beef heifers fed dietery fat supplements containing predominantly saturated or polyunsaturated fatty acids. Theriogenology, $\mathrm{v}$. 45, p. 451-458, 1996.

ZERON, Y; SKALAN, D; ARAV, A. Effect of polyunsaturated fatty acid supplementation on biophysical parameters and chiling sensitivy of ewe oocytes. Molecular Reproduction and Development. v. 62, n. 2, p. 271-278, 2002.

Recebido: 02/08/2005 Aprovado: 20/12/2005 